\title{
Serum lactate dehydrogenase level is associated with in-hospital mortality in critically III patients with acute kidney injury
}

\author{
Dan Zhang ${ }^{1} \cdot$ Lin Shi $^{2}$
}

Received: 14 August 2020 / Accepted: 30 January 2021 / Published online: 15 February 2021

(c) The Author(s), under exclusive licence to Springer Nature B.V. part of Springer Nature 2021

\begin{abstract}
Objective Sixty percent of critically ill patients suffer from acute kidney injury (AKI) and $12 \%$ of them require renal replacement therapy during their ICU stay. However, we lack effective biomarkers to predict the mortality of critically ill patients with AKI. Few studies have investigated the association between lactate dehydrogenase levels and mortality in patients with AKI.

Methods We conducted a retrospective cohort study with large samples, using a large database, the Multi parameter Intelligent Monitoring in Intensive Care III project. Clinical and demographic data were collected from the database by structure query language. Multiple models were constructed by stepwise methods to examine the association between lactate dehydrogenase (LDH) and in-hospital mortality. The predictive performance of LDH was assessed by ROC analysis and $p$ values were calculated for trends.

Results In the final analysis, 8436 patients met the inclusion criteria, and 1519 patients died during their hospital stay. The mortality rate increased with increasing LDH levels. The association between LDH and in-hospital mortality was almost linear $(p<0.001)$. A multiple logistic regression model indicated that LDH level was an independent predictor of in-hospital mortality $(\mathrm{OR}=1.56,95 \% \mathrm{CI}(1.39-1.73), p<0.001)$ and this effect remained stable in the subgroup analysis. Moreover, the combined AUC of LDH and SAPSII was 0.83.

Conclusions The LDH level, which can be easily assessed, is significantly and independently associated with in-hospital mortality, and could increase the predictive ability of SAPSII for in-hospital mortality in our study.
\end{abstract}

Keywords Lactate dehydrogenase $\cdot$ Acute kidney injury $\cdot$ Critical care $\cdot$ Hospital mortality

\section{Introduction}

Acute kidney injury (AKI) is a common and severe complication in critically ill patients, that always results in a poor prognosis and increases short- and long-term mortality [1]. Moreover, the persistent loss of renal function may increase the risk of chronic kidney disease (CKD) or end-stage kidney disease (ESKD) [2]. Among patients in the intensive care unit (ICU), nearly $60 \%$ of critically ill patients may suffer from AKI during their ICU stay, and approximately $12 \%$

Lin Shi

linshi_xuzhou@outlook.com

1 Department of Nephrology, Affiliated Hospital of Xuzhou Medical University, 99 West Huai-hai Road, Xuzhou 221002, Jiangsu, China

2 Department of Gastroenterology, Xuzhou Central Hospital, Xuzhou, Jiangsu, China require renal replacement therapy (RRT) [3]. In particular, the mortality of septic patients with AKI may increase to 45-60\% [4]. Because of the high incidence of AKI and high patient mortality, it is essential to find effective predictors of in-hospital mortality, especially for patients in the ICU.

Lactate dehydrogenase (LDH), a common enzyme involved in energy production, is widely present in nearly all cells in the body, with the highest levels in heart, liver, lungs, muscles, kidneys, and blood cells [5]. LDH is considered an inflammatory biomarker and is always elevated in many diseases, such as lung damage, interstitial lung infections, and atopic dermatitis [5-7]. In addition, the inflammatory process plays an important role in the initiation and progression of AKI $[8,9]$. Based on these findings, the association between LDH levels and AKI has not been clearly clarified, and a few studies to date have explored the prognostic value of LDH in critically ill patients with AKI. 


\section{Materials and methods}

\section{Database and setting}

This was an observational study from a large US-based critical care database called the Multiparameter Intelligent Monitoring in Intensive Care Database III version 1.4(MIMIC-III v1.4). There are over 40,000 medical records from various critical care units at Beth Israel Deaconess Medical Center (Boston, MA, USA) between 2001 and 2012 stored in the database [10]. The database includes 38,597 adults and 7870 newborns, with 58,976 hospital admissions in total. All the medical records in the MIMIC-III database have been de-identified to protect patient privacy. Researchers are allowed to access the database after completing the National Institutes of Health's web-based course known as Protecting Human Research Participants (certification number 25119010) [11]. As there is pre-existing institutional review board (IRB) approval in the MIMIC-III database, we were exempt from IRB approval from our institution. The software pgAdmin (version 1.12.3) was used to extract all data in our study, because the whole database was constructed on the basis of structure query language (SQL).

\section{Study population}

All patients in the MIMIC-III database were eligible for inclusion in the present investigation. The inclusion criteria in our study were (1) an age of 16 years or greater; and (2) an ICU stay longer than $48 \mathrm{~h}$; patients were excluded from our study if (1) $>5 \%$ of their individual data were missing, (2) outliers were present, and (3) they had rhabdomyolysis, a malignant tumor, cardiomyopathy or cardiac arrest, and they had chronic kidney disease (CKD). The outliers were defined as values exceeding the mean \pm 3 times the standard deviation (SD). AKI was defined on the basis of the Kidney disease: improving global outcomes (KDIGO) classification [12]. For patients with multiple admissions, only data from the first ICU admission during the first hospitalization were used.

\section{Data extraction and study variables}

We extracted data during the first $24 \mathrm{~h}$ of ICU admission from the MIMIC-III database by SQL in study patients who met the inclusion criteria. The demographic variables included age at the time of hospital admission, sex, and ethnicity. The clinical variables included the ICU type, sequential organ failure assessment (SOFA) score, Simplified Acute Physiology Score II (SAPSII), Elixhauser comorbidity score, use of vasopressors, use of ventilation, and renal replacement therapy (RRT) [13, 14]. For comorbidities, congestive heart failure (CHF), liver disease, chronic obstructive pulmonary disease (COPD), coronary artery disease (CAD), stroke, and diabetes were included. All of the comorbidities were identified on the basis of the recorded ICD-9 codes. Vital signs included mean heart rate and mean arterial pressure (MAP) in the first 24 ICU admission hours. The laboratory results included the white blood cell (WBC) count, hemoglobin level, platelet count level, albumin level, total bilirubin level, blood urea nitrogen (BUN) level, creatinine level, lactate level, and serum potassium level in the first 24 ICU admission hours.

\section{Study outcome}

The primary outcome of our study was in-hospital mortality, which was defined as the survival status of each patient at the time of hospital discharge.

\section{Statistical methods}

We divided all enrolled patients into three groups according to quartiles of LDH ( $25 \%$ quantile, $75 \%$ quantile). The baseline characteristics of our study population were presented as the frequency (percent) for categorical data and the median with interquartile range. Comparisons of different groups of LDH were made by Student's $t$ or Mann-Whitney $U$ tests, appropriately, for continuous variables and Chi-square tests for categorical variables.

To examine whether there would be an independent association between LDH level and in-hospital mortality for critically ill patients, multivariate logistic regression models based on a forward selection modeling process were built, with LDH treated as a categorical variable by quartiles and the results presented as odds ratios (ORs) with 95\% CIs. The $\mathrm{p}$ of LDH level for trends was also calculated to examine whether a nonlinear relationship existed between in-hospital mortality and LDH. The median value of each category of LDH level was entered into models as a continuous variable [15]. Receiver-operating characteristic (ROC) curve analysis and combined ROC curves [16] were used to evaluate the ability of LDH to discriminate between survivors and nonsurvivors. All the statistical analyses were conducted using R software (version 3.6.3).

\section{Results}

\section{Baseline characteristics}

The initial cohort of our study was 52,963 ICU admissions from the MIMIC-III database. After reviewing all patients in the initial cohort, we identified 15,056 
critically ill patients with AKI. There were 8436 patients with AKI included in our final analysis (Fig. 1). A total of 1519 analyzed patients died including 228 (10.56\%) patients in a group with $\mathrm{LDH}<203 \mathrm{U} / \mathrm{L}, 717$ (16.98\%) patients in a group with LDH 203-392 U/L and 574 (27.95\%) patients in a group with $\mathrm{LDH}>392 \mathrm{U} / \mathrm{L}$. In our study, all 1519 patients died in the hospital. The causes of death were sepsis (811 patients), respiratory failure (229 patients), cardiac dysfunction (196 patients), liver cirrhosis (189 patients), and electrolyte disturbances (58 patients). For 36 patients, no specific causes of death was indicated in the discharge summary of the database.

The baseline characteristics of our study cohort are summarized in Table 1 which shows the different groups of LDH levels. In general, patients with higher LDH levels were more critically ill than patients with the lower LDH levels [SOFA 4 (2-7) vs. 5 (3-8) vs. 6 (4-9); $p<0.001$ ], [SAPSII $37(29-47)$ vs. 39 (31-48) vs. 41 (32-52); $p<0.001]$. A significantly larger percentage of the patients with higher LDH levels received mechanical ventilation ( $30.99 \%$ vs. $42.69 \%$ vs. $54.48 \%$ ), vasopressor treatment ( $7.36 \%$ vs. $10.21 \%$ vs. $16.36 \%$ ), and renal replacement therapy $(2.59 \%$ vs. $3.29 \%$ vs. $8.91 \%)$ during the first $24 \mathrm{~h}$ of their ICU stay. Moreover, patients with higher LDH levels had a higher incidence of stage 3 AKI (16.22\% vs. $17.74 \%$ vs. $23.71 \%)$.

\section{Association between LDH level and in-hospital mortality}

To determine the independent association between LDH level and in-hospital mortality, we developed three multivariable logistic regression models using a forward selection method. The adjusted factors of each model are shown in the Methods section and in Table 2. In model one, without any adjustments, the LDH level was associated with in-hospital mortality [OR $=1.83,95 \% \mathrm{CI}(1.68-1.98), p<0.001]$, which indicated that the in-hospital mortality rate increased by $83 \%$ with each increment in the LDH level. In model two, we adjusted data for age and sex, and the odds ratio was 1.87 with a 95\% CI 1.02-2.03. The LDH level was significantly associated with mortality. In the final model, the LDH level was still significantly associated with in-hospital mortality $[\mathrm{OR}=1.32,95 \% \mathrm{CI}(1.24-1.40), p<0.001]$, which indicated that the in-hospital mortality rate increased by $56 \%$ with each increment in the LDH level after adjusting for multiple variables. We also identified the SAPSII $(\mathrm{OR}=1.02$, $p<0.001)$, Elixhauser score ( $\mathrm{OR}=1.03, p<0.001)$, and vasopressin use $(\mathrm{OR}=2.76, p<0.001)$ as predictors of inhospital mortality.

The $\mathrm{P}$ value for the trend of the LDH value was also calculated in model three by R software to examine whether a nonlinear relationship existed between in-hospital mortality and LDH, which is also shown in Table 3. Compared with that of group A, the ORs of groups B and C were 1.45-2.12,
Fig. 1 Flowchart of inclusion and exclusion criteria to select final study population

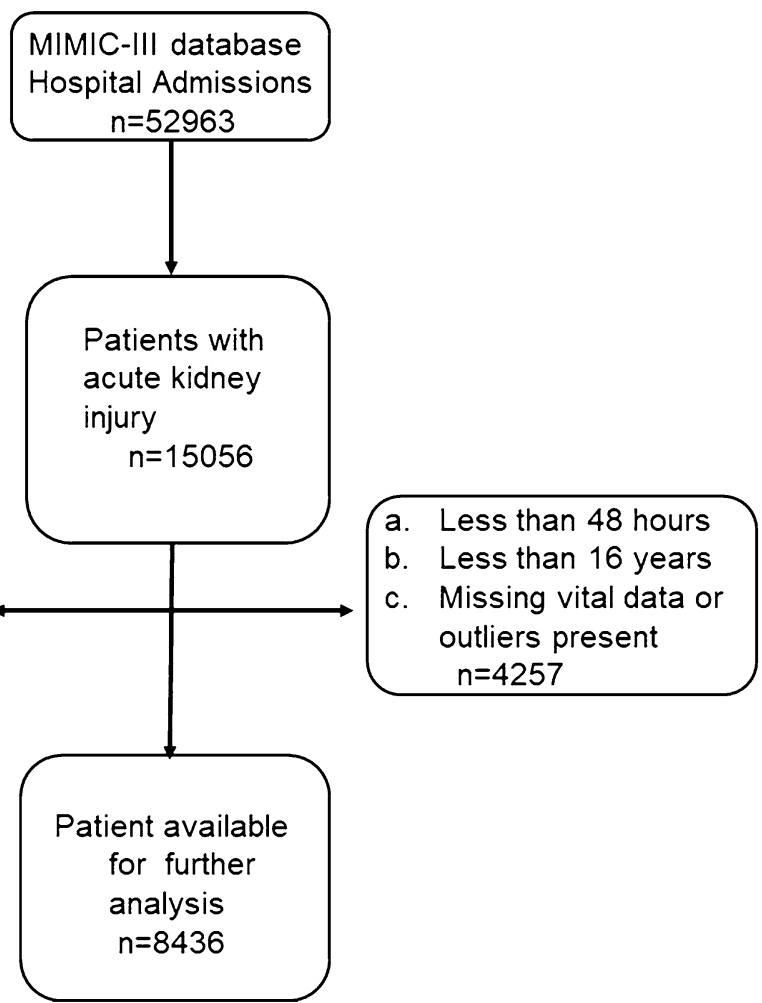


Table1 Baseline characteristics of the study population with different LDH level

\begin{tabular}{|c|c|c|c|c|}
\hline LDH level & $<203$ & $203-392$ & $>392$ & $p$ value \\
\hline Clinical parameters, $n(\%)$ & 2159 & 4223 & 2054 & \\
\hline Age, years & $64.21 \pm 16.73$ & $64.77 \pm 16.52$ & $60.97 \pm 17.62$ & $<0.001$ \\
\hline Sex, $n(\%)$ & & & & 0.027 \\
\hline Female & $902(41.78 \%)$ & $1864(44.14 \%)$ & $942(45.86 \%)$ & \\
\hline Male & $1257(58.22 \%)$ & $2359(55.86 \%)$ & $1112(54.14 \%)$ & \\
\hline \multicolumn{5}{|l|}{ Ethnicity, $n(\%)$} \\
\hline White & $1698(74.48 \%)$ & $3056(72.37 \%)$ & $1368(66.60 \%)$ & \\
\hline Black & $177(8.20 \%)$ & $322(7.62 \%)$ & $191(9.30 \%)$ & \\
\hline Other & $374(17.32 \%)$ & $845(20.01 \%)$ & $495(24.10 \%)$ & \\
\hline Length of ICU stay, days & $7.12 \pm 8.11$ & $8.63 \pm 9.19$ & $9.93 \pm 10.08$ & $<0.001$ \\
\hline Heart rate, beats/minute & 86.14 (75.55-98.70) & $88.46(78.03-100.43)$ & $92.27(80.37-104.37)$ & $<0.001$ \\
\hline $\mathrm{SBP}, \mathrm{mmHg}$ & $112.40(104.09-123.04)$ & $113.98(104.61-126.45)$ & $112.55(103.88-125.29)$ & $<0.001$ \\
\hline $\mathrm{DBP}, \mathrm{mmHg}$ & $57.60(51.75-64.86)$ & $58.96(52.58-66.42)$ & $60.83(54.17-67.76)$ & $<0.001$ \\
\hline Vasopressin use, $n(\%)$ & $159(7.36 \%)$ & $431(10.21 \%)$ & $336(16.36 \%)$ & $<0.001$ \\
\hline Ventilator use, $n(\%)$ & $669(30.99 \%)$ & $1803(42.69 \%)$ & $1119(54.48 \%)$ & $<0.001$ \\
\hline CRRT, $n(\%)$ & $56(2.59 \%)$ & $139(3.29 \%)$ & $183(8.91 \%)$ & $<0.001$ \\
\hline \multicolumn{5}{|l|}{ Laboratory parameters } \\
\hline White blood cell count, $10^{9} / \mathrm{L}$ & $10.90(7.60-15.10)$ & $11.40(8.00-16.25)$ & $12.45(8.50-17.90)$ & $<0.001$ \\
\hline Platelet count, $10^{9} / \mathrm{L}$ & $196.00(132.00-279.00)$ & $192.00(130.00-269.50)$ & $180.00(111.00-261.00)$ & $<0.001$ \\
\hline Hemoglobin, g/dL & $10.30(9.00-11.80)$ & $10.50(9.20-12.00)$ & $10.70(9.20-12.30)$ & $<0.001$ \\
\hline BUN, mg/dl & $20(13-32)$ & $22(15-35)$ & $23(15-38)$ & $<0.001$ \\
\hline Albumin, g/L & $32(26-37)$ & $31(26-36)$ & $31(26-35)$ & $<0.001$ \\
\hline Total bilirubin, mg/dL & $0.50(0.30-0.90)$ & $0.60(0.40-1.20)$ & $0.80(0.50-1.70)$ & $<0.001$ \\
\hline Creatinine, $\mathrm{mg} / \mathrm{dL}$ & $1.1(0.9-1.6)$ & $1.2(1.0-1.8)$ & $1.4(1.0-2.2)$ & $<0.001$ \\
\hline INR & $1.30(1.20-1.60)$ & $1.30(1.20-1.70)$ & $1.40(1.20-1.80)$ & $<0.001$ \\
\hline $\mathrm{PO} 2, \mathrm{mmHg}$ & $149.75(102.00-216.28)$ & $145.67(102.37-208.86)$ & $135.00(97.00-190.32)$ & $<0.001$ \\
\hline $\mathrm{PCO} 2, \mathrm{mmHg}$ & $40.00(35.75-44.75)$ & $39.79(35.50-44.55)$ & $39.00(34.29-43.78)$ & $<0.001$ \\
\hline Plasma lactate & $1.80(1.25-2.70)$ & $2.00(1.40-3.02)$ & $2.42(1.57-4.10)$ & $<0.001$ \\
\hline Potassium concentration, $\mathrm{mmol} / \mathrm{L}$ & $4.00(3.60-4.50)$ & $4.10(3.60-4.50)$ & $4.10(3.70-4.60)$ & $<0.001$ \\
\hline Sodium concentration, $\mathrm{mmol} / \mathrm{L}$ & $137(135-141)$ & $138(134-140)$ & $139(137-143)$ & 0.01 \\
\hline \multicolumn{5}{|l|}{ Comorbidities } \\
\hline Hypertension, $n(\%)$ & $1086(50.30 \%)$ & $2041(48.33 \%)$ & $866(42.16 \%)$ & $<0.001$ \\
\hline Chronic pulmonary, $n(\%)$ & $517(23.95 \%)$ & $1040(24.63 \%)$ & $429(20.89 \%)$ & $<0.001$ \\
\hline Diabetes, $n(\%)$ & $582(26.96 \%)$ & $1152(27.28 \%)$ & $440(21.42 \%)$ & $<0.001$ \\
\hline Liver disease, $\mathrm{n}(\%)$ & $302(13.99 \%)$ & $693(16.41 \%)$ & $542(26.39 \%)$ & $<0.001$ \\
\hline Coronary heart disease, $n(\%)$ & $575(26.63 \%)$ & $1034(24.48 \%)$ & $509(24.78 \%)$ & $<0.001$ \\
\hline Stroke, $n(\%)$ & $302(13.99 \%)$ & $693(16.41 \%)$ & $542(26.39 \%)$ & $<0.001$ \\
\hline Chronic heart failure, $n(\%)$ & $605(28.02 \%)$ & $1525(36.11 \%)$ & $747(36.37 \%)$ & $<0.001$ \\
\hline AKI stage & & & & $<0.001$ \\
\hline Stage 1 & $949(43.98 \%)$ & $1727(40.90 \%)$ & $728(35.44 \%)$ & \\
\hline Stage 2 & $859(39.81 \%)$ & $1747(41.37 \%)$ & $839(40.85 \%)$ & \\
\hline Stage 3 & $350(16.22 \%)$ & $749(17.74 \%)$ & $487(23.71 \%)$ & \\
\hline Elixhauser comorbidity score & $6.47 \pm 6.89$ & $6.78 \pm 6.94$ & $6.85 \pm 6.88$ & 0.133 \\
\hline \multicolumn{5}{|l|}{ Scoring system } \\
\hline SOFA & $4(2-7)$ & $5(3-8)$ & $6(4-9)$ & $<0.001$ \\
\hline SAPSII & $37(29-47)$ & $39(31-48)$ & $41(32-52)$ & $<0.001$ \\
\hline In-hospital mortality & $228(10.56 \%)$ & $717(16.98 \%)$ & $574(27.95 \%)$ & $<0.001$ \\
\hline
\end{tabular}

$C R R T$ continuous renal replacement therapy, $B U N$ blood urea nitrogen, INR international normalized ratio 
Table 2 ORs (95\% CIs) for all-cause in-hospital mortality across groups of LDH level

\begin{tabular}{lllll}
\hline Models & \multicolumn{2}{l}{ Odds ratio (95\% confidence interval), $p$ value } & $p$ for trend \\
\cline { 2 - 4 } & & OR $(95 \%$ CI $)$ & $p$ value & \\
\hline Model 1 & Level A vs. level B and C & $1.83(1.68-1.98)$ & $<0.001$ & $<0.001$ \\
Model 2 & Level A vs. level B and C & $1.87(1.02-2.03)$ & $<0.001$ & $<0.001$ \\
Model 3 & Level A vs. level B and C & $1.32(1.24-1.40)$ & $<0.001$ & $<0.001$ \\
\hline
\end{tabular}

Model 1. Adjusted for age, sex, and ethnicity

Model 2 Adjusted for model 1 plus history of diabetes, coronary heart disease, hypertension, chronic pulmonary disease, history liver disease, and stroke

Model 3. Adjusted for model 2 plus white blood cells, platelets, hemoglobin, creatinine, bun, INR, and total bilirubin. Albumin, SAPSII, SOFA, systolic blood pressure, diastolic blood pressure, heart rate, lactate, length of hospital stay, renal replacement therapy, use of vasopressin, and use of ventilator

Level A LDH value < 203 U/L, Level B LDH value in 203 U/L-392 U/L, Level C LDH value > 392 U/L respectively. The ORs were equidirectional, and more than once, the $p$ value for trends was less than 0.001 , which also indicate a linear relationship between the $\mathrm{LDH}$ value and in-hospital mortality.

\section{Subgroup analysis and ROC curve analysis}

ROC curves were generated to evaluate the ability of LDH to discriminate between survivors and non-survivors. The area under the curve of LDH was 0.75. A combined ROC curve for SAPSII and LDH was performed to examine whether LDH could increase the predictive ability of SAPSII. The AUCs of the combined curve and SAPSII were 0.83 and 0.77 , respectively (Fig. 2).

A subgroup analysis based on model three was also conducted and no significant interaction was observed in the analysis. In different subgroups, the LDH was still an independent indicator of in-hospital mortality (Table 3).

\section{Discussion}

We conducted a large retrospective cohort study that enrolled 8436 critically ill patients with AKI during their ICU stay from a large database, the MIMIC-III database, and the study demonstrated that the LDH level was associated with in-hospital mortality and that LDH values were significantly increased in non-surviving patients with AKI. Subsequently, we developed three multivariate models, and factors were entered into our models by stepwise methods. After adjusting for many relevant factors, the LDH level was still an independent predictor of in-hospital mortality in patients with AKI. There were no significant interactions in any strata in the subgroup analysis, and the association between the LDH value and in-hospital mortality was linear. Moreover, the combination of LDH and SAPSII could predict in-hospital mortality more effectively than each single variables. All these findings show that LDH can be an effective tool to predict the prognosis of AKI patients in the ICU.

LDH catalyzes the reversible transformation of pyruvate to lactate and plays a central role in anaerobic cellular metabolism $[17,18]$. This hypoxia-inducible factor regulates the production of LDH transcription when the body is in a state of hypoxia [19]. Usually, LDH is released into serum as a biomarker of cell membrane damage, platelet activation, and angiogenesis [20]. Several studies have assessed the association between LDH and many diseases. Guan et al. suggested that a high LDH level was an independent risk factor for cardiac surgery-associated AKI and multiple wasp stings associated with AKI [21, 22]. In some studies, LDH was an indicator of interstitial lung infections and atopic dermatitis [5, 7]. In addition, previous studies have shown that LDH levels may increase in patients with malignant tumors and that it can be considered a good predictor of prognosis in patients with gastric cancer [23]. Furthermore, LDH has long been considered a predictor of disease severity, as it has high morbidity and mortality in critically ill patients. In our study, we had similar results; with increasing LDH values, the SOFA and SAPSII scores also increased [24, 25].

AKI is one of the most common complications in critically ill patients, and it varies considerably in terms of the disease severity, progressive course, and eventual prognosis [2]. Local and systematic inflammation are involved in both AKI and CKD progression [26]. Moreover, critically ill patients are always exposed to hypoxia and anaerobic tissue, which results in the rapid accumulation of pyruvate, and pyruvate may be converted into lactate in some circumstances [27]. However, patients with AKI always suffer from lactate dehydrogenase dysfunction, and they are not able to clear endogenous acid production, which causes high levels of LDH [28, 29].

Moreover, in the fully adjusted model, our study also identified lactate, SAPSII score, SOFA score, Elixhauser score, and vasopressin use as significant predictors of inhospital mortality. Although the SAPSII score and the 
Table 3 Subgroup analysis of the associations between LDH and inhospital mortality

\begin{tabular}{|c|c|c|c|}
\hline & $N$ & OR; 95\% CI & $p$ for interaction \\
\hline \multicolumn{4}{|c|}{ Age, years } \\
\hline$\leqq 65$ & 4182 & $1.55(1.35-1.78)$ & \multirow[t]{2}{*}{0.286} \\
\hline$>65$ & 4254 & $1.63(1.45-1.84)$ & \\
\hline \multicolumn{4}{|l|}{ Sex } \\
\hline Female & 3708 & $1.51(1.32-1.72)$ & \multirow[t]{2}{*}{0.194} \\
\hline Male & 4728 & $1.58(1.40-1.78)$ & \\
\hline \multicolumn{4}{|l|}{ SOFA } \\
\hline$\leqq 5$ & 4590 & $1.63(1.42-1.89)$ & \multirow[t]{2}{*}{0.36} \\
\hline$>5$ & 3846 & $1.5(1.33-1.67)$ & \\
\hline \multicolumn{4}{|l|}{ SAPSII } \\
\hline$\leqq 39$ & 4408 & $1.59(1.36-1.86)$ & \multirow[t]{2}{*}{0.42} \\
\hline$>39$ & 4028 & $1.51(1.35-1.68)$ & \\
\hline \multicolumn{4}{|c|}{ Liver disease } \\
\hline Yes & 1537 & $1.4(1.17-1.67)$ & \multirow[t]{2}{*}{0.161} \\
\hline No & 6899 & $1.57(1.41-1.74)$ & \\
\hline \multicolumn{4}{|l|}{ Diabetes } \\
\hline Yes & 2174 & $1.46(1.22-1.76)$ & \multirow[t]{2}{*}{0.191} \\
\hline No & 6262 & $1.56(1.41-1.73)$ & \\
\hline \multicolumn{4}{|c|}{ Hypertension } \\
\hline Yes & 3993 & $1.72(1.5-1.98)$ & \multirow[t]{2}{*}{0.167} \\
\hline No & 4443 & $1.43(1.28-1.61)$ & \\
\hline \multicolumn{4}{|c|}{ Chronic heart failure } \\
\hline Yes & 2877 & $1.48(1.28-1.72)$ & \multirow[t]{2}{*}{0.213} \\
\hline No & 5559 & $1.58(1.41-1.76)$ & \\
\hline \multicolumn{4}{|l|}{ Stroke } \\
\hline Yes & 756 & $1.42(1.08-1.87)$ & \multirow[t]{2}{*}{0.234} \\
\hline No & 7680 & $1.58(1.43-1.73)$ & \\
\hline \multicolumn{4}{|c|}{ Coronary heart disease } \\
\hline Yes & 2118 & $2.03(1.64-2.52)$ & \multirow[t]{2}{*}{0.157} \\
\hline No & 6318 & $1.47(1.33-1.63)$ & \\
\hline \multicolumn{4}{|c|}{ Chronic pulmonary } \\
\hline Yes & 1986 & $1.52(1.26-1.85)$ & \multirow[t]{2}{*}{0.219} \\
\hline No & 6450 & $1.56(1.4-1.72)$ & \\
\hline \multicolumn{4}{|c|}{ Vasopressin use } \\
\hline Yes & 926 & $1.59(1.3-1.94)$ & \multirow[t]{2}{*}{0.3} \\
\hline No & 7510 & $1.52(1.38-1.69)$ & \\
\hline Ventilator & & & \\
\hline Yes & 3591 & $1.47(1.31-1.66)$ & 0.223 \\
\hline No & 4845 & $1.64(1.42-1.88)$ & \\
\hline CRRT & & & \\
\hline Yes & 378 & $1.51(1.13-2.02)$ & 0.653 \\
\hline No & 8058 & $1.6(1.46-1.76)$ & \\
\hline AKI stage & & & \\
\hline Stage 1 & 3404 & $1.66(1.38-2.01)$ & 0.321 \\
\hline Stage 2 & 3445 & $1.51(1.31-1.75)$ & \\
\hline Stage 3 & 1587 & $1.41(1.17-1.66)$ & \\
\hline
\end{tabular}

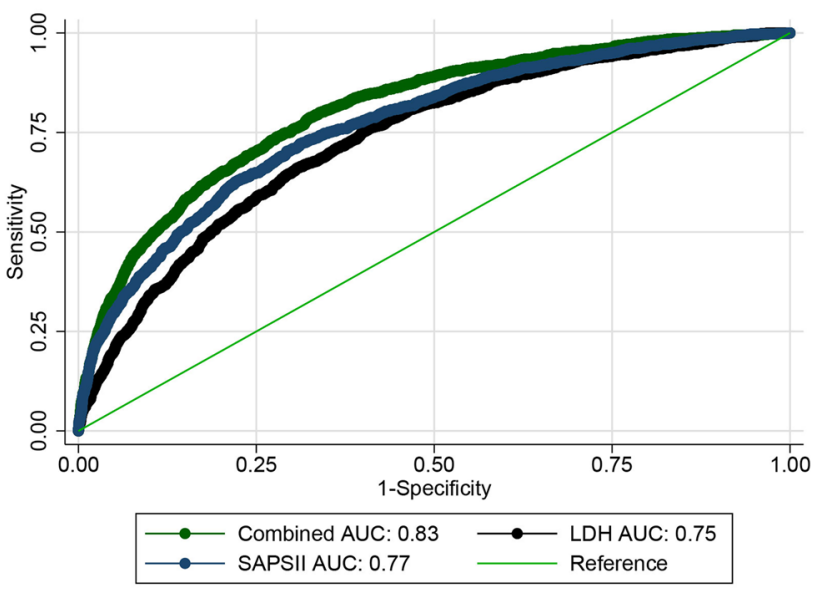

Fig. 2 Performance in predicting in-hospital mortality using LDH, SAPSII and combined ROC

SOFA score have been widely used in critically ill patients to predict short-term mortality, the complex scoring systems required approximately $24 \mathrm{~h}$ to complete and, thus, cannot evaluate disease conditions in a timely manner [30]. Traditionally, vasopressin use can stabilize blood pressure, and it has been assumed to be an effective therapy for critically ill patients. However, recent studies have indicated that vasopressin use is an independent risk factor for mortality, especially in critically ill patients, which is in accordance with our results [31]. The underlying mechanisms require exploration with further research.

There were several limitations in our study. First, our study was a retrospective and observational study. Second, LDH values were included in our study only in the first $24 \mathrm{~h}$ during the ICU stay, and the use of a single measure for LDH may have had an impact on the accuracy of the results. Finally, well-designed prospective and randomizedcontrolled trials are needed to further demonstrate the association between in-hospital mortality and LDH level.

\section{Conclusion}

In this large retrospective cohort study, with the use of a large database, we found that the LDH level was independently associated with in-hospital mortality in critically patients with AKI. The association between the LDH value and mortality was linear. LDH could increase the predictive ability of SAPSII for in-hospital mortality in our study.

Author contributions DZ (first author): study design; critical revision of the manuscript for important intellectual content; study supervision; manuscript writing; final approval of manuscript. E-mail:doc_ dan_zhang@163.com. LS (corresponding author): study concept and design; acquisition of data; analysis and interpretation of data; drafting 
of the manuscript; critical revision of the manuscript for important intellectual content; statistical analysis; final approval of manuscript. E-mail: linshi_xuzhou@outlook.com. All authors read and approved the final manuscript.

Funding This article has no fund support.

Data availability All the data are available in MIMIC-III database: MIMIC-III, a freely accessible critical care database. Johnson AEW, Pollard TJ, Shen L, Lehman L, Feng M, Ghassemi M, Moody B, Szolovits P, Celi LA, and Mark RG. Scientific Data (2016). https:// doi.org/10.1038/sdata.2016.35.

\section{Compliance with ethical standards}

Conflict of interest The authors declare that they have no competing interests.

Ethical approval All procedures performed in studies involving human participants were in accordance with the ethical standards of the institutional and/or national research committee and with the 1964 Helsinki Declaration and its later amendments or comparable ethical standards. Informed consent was obtained from all individual participants included in the study.

\section{References}

1. Darmon M, Ostermann M, Cerda J, Dimopoulos MA, Forni L, Hoste E, Legrand M, Lerolle N, Rondeau E, Schneider A et al (2017) Diagnostic work-up and specific causes of acute kidney injury. Intensive Care Med 43(6):829-840

2. Hoste EA, Bagshaw SM, Bellomo R, Cely CM, Colman R, Cruz DN, Edipidis K, Forni LG, Gomersall CD, Govil D et al (2015) Epidemiology of acute kidney injury in critically ill patients: the multinational AKI-EPI study. Intensive Care Med 41(8):1411-1423

3. Chawla LS, Eggers PW, Star RA, Kimmel PL (2014) Acute kidney injury and chronic kidney disease as interconnected syndromes. New Engl J Med 371(1):58-66

4. Mehta RL, Bouchard J, Soroko SB, Ikizler TA, Paganini EP, Chertow GM, Himmelfarb J (2011) Sepsis as a cause and consequence of acute kidney injury: program to improve care in acute renal disease. Intensive Care Med 37(2):241-248

5. Poggiali E, Zaino D, Immovilli P, Rovero L, Losi G, Dacrema A, Nuccetelli M, Vadacca GB, Guidetti D, Vercelli A et al (2020) Lactate dehydrogenase and C-reactive protein as predictors of respiratory failure in CoVID-19 patients. Clin Chim Acta 509:135-138

6. McFadden RG, Oliphant LD (1991) Serum lactate dehydrogenase in interstitial lung disease. Chest 100(4):1182

7. Kato A, Kamata M, Ito M, Uchida H, Nagata M, Fukaya S, Hayashi K, Fukuyasu A, Tanaka T, Ishikawa T et al (2020) Higher baseline serum lactate dehydrogenase level is associated with poor efectiveness of dupilumab in the long term in patients with atopic dermatitis. J Dermatol 47(9):1013-1019

8. Rabb H, Griffin MD, McKay DB, Swaminathan S, Pickkers P, Rosner MH, Kellum JA, Ronco C (2016) Inflammation in AKI: current understanding key questions, and knowledge gaps. J Am Soc Nephrol JASN 27(2):371-379

9. Mami I, Tavernier Q, Bouvier N, Aboukamis R, Desbuissons G, Rabant M, Poindessous V, Laurent-Puig P, Beaune P, Tharaux PL et al (2016) A novel extrinsic pathway for the unfolded protein response in the kidney. J Am Soc Nephrol JASN 27(9):2670-2683

10. Johnson AE, Pollard TJ, Shen L, Lehman LW, Feng M, Ghassemi M, Moody B, Szolovits P, Celi LA, Mark RG (2016) MIMIC-III, a freely accessible critical care database. Scie Data 3:160035

11. Shi L, Zhang D (2020) Proton pump inhibitor use before icu admission is not associated with mortality of critically Ill patients. J Clin Pharmacol 60(7):860-866

12. Mehta RL, Kellum JA, Shah SV, Molitoris BA, Ronco C, Warnock DG, Levin A (2007) Network acute kidney injury, acute kidney injury network: report of an initiative to improve outcomes in acute kidney injury. Crit Care 11(2):R31

13. Vincent JL, Moreno R, Takala J, Willatts S, De Mendonca A, Bruining H, Reinhart CK, Suter PM, Thijs LG (1996) The SOFA (Sepsis-related Organ Failure Assessment) score to describe organ dysfunction/failure on behalf of the working group on sepsisrelated problems of the European society of intensive care medicine. Intensive Care Med 22(7):707-710

14. van Walraven C, Austin PC, Jennings A, Quan H, Forster AJ (2009) A modification of the Elixhauser comorbidity measures into a point system for hospital death using administrative data. Med Care 47(6):626-633

15. Park SY, Freedman ND, Haiman CA, Le Marchand L, Wilkens LR, Setiawan VW (2017) Association of coffee consumption with total and cause-specific mortality among nonwhite populations. Ann Intern Med 167(4):228-235

16. Takahashi K, Uchiyama H, Yanagisawa S, Kamae I (2006) The logistic regression and ROC analysis of group-based screening for predicting diabetes incidence in 4 years. Kobe $\mathrm{J}$ Med Sci 52(6):171-180

17. Kottmann RM, Kulkarni AA, Smolnycki KA, Lyda E, Dahanayake T, Salibi R, Honnons S, Jones C, Isern NG, Hu JZ et al (2012) Lactic acid is elevated in idiopathic pulmonary fibrosis and induces myofibroblast differentiation via $\mathrm{pH}$-dependent activation of transforming growth factor-Hz . Am J Respir Crit Care Med 186(8):740-751

18. Castello-Cros R, Whitaker-Menezes D, Molchansky A, Purkins G, Soslowsky LJ, Beason DP, Sotgia F, Iozzo RV, Lisanti MP (2011) Scleroderma-like properties of skin from caveolin-1-deficient mice: implications for new treatment strategies in patients with fibrosis and systemic sclerosis. Cell Cycle (Georget Tex) 10(13):2140-2150

19. Draoui N, Feron O (2011) Lactate shuttles at a glance: from physiological paradigms to anti-cancer treatments. Dis Models Mech 4(6):727-732

20. Egan K, Singh V, Gidron A, Mehta J (2007) Correlation between serum lactate dehydrogenase and stem cell mobilization. Bone Marrow Transplant 40(10):931-934

21. Guan C, Li C, Xu L, Zhen L, Zhang Y, Zhao L, Zhou B, Che L, Wang Y, Xu Y (2019) Risk factors of cardiac surgery-associated acute kidney injury: development and validation of a perioperative predictive nomogram. J Nephrol 32(6):937-945

22. Yuan H, Lu L, Gao Z, Hu F (2020) Risk factors of acute kidney injury induced by multiple wasp stings. Toxic Off J Int Soc Toxinol 182:1-6

23. Yu M, Chen S, Hong W, Gu Y, Huang B, Lin Y, Zhou Y, Jin H, Deng Y, Tu L et al (2019) Prognostic role of glycolysis for cancer outcome: evidence from 86 studies. J Cancer Res Clin Oncol 145(4):967-999

24. Chen T, Wu D, Chen H, Yan W, Yang D, Chen G, Ma K, Xu D, Yu $\mathrm{H}$, Wang $\mathrm{H}$ et al (2020) Clinical characteristics of 113 deceased patients with coronavirus disease 2019: retrospective study. BMJ (Clin Res) 368:m1091

25. Gotta V, Tancev G, Marsenic O, Vogt JE, Pister M (2020) Identifying key predictors of mortality in young patients on chronic haemodialysis-a machine learning approach, Nephrology, dialysis, 
transplantation. Of Publ Eur Dialysis Transplant Assoc Eur Renal Assoc 35:i48-55

26. Zheng CF, Liu WY, Zeng FF, Zheng MH, Shi HY, Zhou Y, Pan JY (2017) Prognostic value of platelet-to-lymphocyte ratios among critically ill patients with acute kidney injury. Crit Care 21(1):238

27. Sun DQ, Zhang L, Zheng CF, Liu WY, Zheng KI, Chen XM, Zheng MH, Yuan WJ (2019) Metabolic acidosis in critically ill cirrhotic patients with acute kidney injury. J Clin Translational Hepatol 7(2):112-121

28. Levy B, Gibot S, Franck P, Cravoisy A, Bollaert PE (2005) Relation between muscle $\mathrm{Na}+\mathrm{K}+$ ATPase activity and raised lactate concentrations in septic shock: a prospective study. Lancet (Lond Engl) 365(9462):871-875

29. Cheng B, Li D, Gong Y, Ying B, Wang B (2020) Serum anion gap predicts all-cause mortality in critically Ill patients with acute kidney injury: analysis of the MIMIC-III database. Dis Markers 2020:1-10
30. Dettmer MR, Damuth E, Zarbiv S, Mitchell JA, Bartock JL, Trzeciak S (2017) Prognostic factors for long-term mortality in critically Ill patients treated with prolonged mechanical ventilation: a systematic review. Crit Care Med 45(1):69-74

31. Aoki M, Abe T, Saitoh D, Hagiwara S, Oshima K (2018) Use of vasopressor increases the risk of mortality in traumatic hemorrhagic shock: a nationwide cohort study in Japan. Crit Care Med 46(12):e1145-e1151

Publisher's Note Springer Nature remains neutral with regard to jurisdictional claims in published maps and institutional affiliations. 